\title{
Cobalt and Zinc in Toenails of Some Kano Inhabitants
}

\author{
*J.T. Ayodele and I.C. Ajala \\ Department of pure and Industrial Chemistry Bayero University, P.M.B.301; Kano-Nigeria \\ [*Corresponding Author: e-mail tjayodele@yahoo.com]
}

\begin{abstract}
Quantitative determination of $\mathrm{Co}$ and $\mathrm{Zn}$ concentrations in toenails of 42 volunteers with a mean age of $25.01 \pm 11.46$ years and resident in Kano for at least six months were assayed by atomic absorption (AAS). .Significantly high levels of $\mathrm{Co}$ and $\mathrm{Zn}$ were present in the toenails of some individuals with a mean Co of $75.72 \pm 24.67 \mu \mathrm{g} / \mathrm{g}$ and $108.51 \pm 61.40 \mu \mathrm{g} / \mathrm{g}$ for Co and Zn respectively. With respect to age there was increase relation in zinc concentrations with age with approximate average of $18 \%$ in its concentrations with each decade but no such uniform pattern for the cobalt concentrations.
\end{abstract}

Keywords: Cobalt, Zinc, toenails, Kano, Nigeria.

\section{INTRODUCTION}

Toenail is a biological specimen that is easily and non invasively collected with minimum cost, easily stored and transported thus making toenail an attractive bio-monitoring substrate (Hayasi et al., 1993; Oluwole et al., 1994; Chaudhary et al., 1995; Vance et al., 1988). Since trace elements are excreted in toenails many have suggested it for assessing their exposure, particularly in developing countries where specialized laboratory services may be unavailable and resources are limited (Schumacher et al., 1991). The ability to distinguish between endogenous trace metals namely absorbed into the blood and incorporated into the toe nails matrix, exogenous and those derived from external contamination is a problem. During the wash step it is assumed that exogenous trace metals are removed, whereas endogenous ones are not. Another issue is the variation in the metal concentration profile among various subpopulations according to age, sex, and toenail (Wolfsperger et al., 1994). Thus it is difficult to establish reference ranges because confounding factors may impose restrictions on the interpretation of individual results.

Man may be exposed to cobalt by breathing, drinking and eating food when cobalt is widely dispersed in the environment. Skin contact with soil or water containing cobalt also enhances exposure. It is found in phosphate fertilizers, tobacco smoke and in burning of coal oil (ATSDR, 2003; Soliman et al., 2006).
Cobalt is beneficial to man because it is part of vitamin $B_{12}$, essential for health. It is used to treat anaemia in pregnant women because it stimulates the production of red blood cells (ATSDR, 2003). Other health effects caused by high concentrations of cobalt are vomiting and nausea, vision and heart problems and thyroid damage (ATSDR, 2003). Cobalt is a possible carcinogen since animalsô studies has shown that cobalt causes cancer when placed directly into muscles or under skin but did not cause cancer in animals that were exposed to it in the air, food or drinking water (ATSDR, 2003).

The need for zinc in human nutrition was demonstrated with the discovery of metabolic process in which this mineral acts as an enzymatic factor (Guthrie and Picciano, 1995). Zinc participates as a component of various proteins, hormones and nucleotide (Guthrie and Picciano; 1995). Zinc deficiency is a public health concern. The extent of the problem is unclear because there is no well established method to assess the zinc status of an individual. Physiological signs of zinc deficiency include depressed growth, anorexia, diarrhoea, parakeratotic and impaired testicular development, immune functions and cognition function (Nielsen, 2002). Pathological signs of zinc deficiency include dwarfism, delayed puberty, failure to thrive, impaired wound healing and increased susceptibility to infectious disease (Nielsen, 2002). Low zinc status increases the susceptibility to osteoporosis and to changes caused by the presence of excessive reactive 
oxygen species or free radicals (Nielsen, 2002).

The adult human body possesses approximately 1.5 to $2.0 \mathrm{~g}$ of zinc of which $80 \%$ is found in bones, muscles, liver, skin, ocular retina, hair and nails (Krebs et al., 1995). It is found in the pancreas, kidney and other body fluids such as prostrate and sperm (Krebs et al., 1995). However, long term high doses of zinc causes digestive problems, decreased cholesterol and defects in immune system function. Zinc concentrations in hair, nails, plasma, blood cells and urine excreted is reduced in the presence of severe deficiency (Gibson, 1989). when in short supply the following activities maybe decreased viz plasma alkaline phosphates, liver, retina and testes alcohol dehydrogenase and connective tissues, thymodine kinase, pancreatic carboxyl peptidase A and liver nuclear DNA -dependent RNA-polymerase (Hambidge and Krebs, 1987, Miller et al., 1979). It is associated with taste and small acuity, wound and burn healing (Hambidge and Krebs, 1987). This study was aimed to investigate cobalt and zinc in toenails of inhabitants residents in Kano and at identifying the sources of exposure contributing to the concentrations of these elements

\section{MATERIALS AND METHODS Sample Collection}

The collected toenail samples were washed using the standard procedure (IAEA, 1997). Volunteers were asked to wash their feet with water and soap devoid of metal contamination, followed by drying with clean towel or tissue paper to remove any external contamination. Using clean stainless steel scissors toenail samples were collected from the toes. Respondents provided toenail clippings and completed questionnaires regarding age and gender. Toenail samples were washed, hot-block digested, and analyzed for Co and $\mathrm{Zn}$. For subsequent analysis, each nail sample was sealed in plastic cover till it was rewashed, dried, digested and converted into water-clear solution.

\section{Sample Treatment}

The procedure involved 6 steps of washing each sample in a clean beaker in an ultrasonic bath, with $25 \mathrm{~cm}^{3}$ portions successively, water, acetone, $1 \%$ detergent solution, water, water, acetone, water, decanting the wash liquid after 10-minute wash (Gammelgaard et al., 1991; Kucera et al.,1996). After washing the samples were air dried and kept in a plastic container.

\section{Analysis}

The concentrations of metals were assayed by Flame Atomic Absorption on a Buck Model 210 VGP Spectrophotometer with air acetylene flame. A series of standards were prepared in deionised water for instrumental calibration by diluting commercial standards containing $1000 \mathrm{mg} / \mathrm{dm}^{3}$ of the metals concentration.The main instrumental parameters like band width, lamp current and wavelength for estimation of metals by AAS were set-up separately for each metal (Mehra and Juneja, 2005).

Each sample $(0.5 \mathrm{~g})$ was digested in $10 \mathrm{~cm}^{3}$ concentrated $\mathrm{HNO}_{3}$ and the resulting solution was evaporated to dryness and redissolved in $0.1 \mathrm{M}$ nitric acid. The result of the absorbance and scattering were compensated for by deuterium hollow cathode lamp. De-ionised water was digested as blank using the same procedure previously described (Ayodele and Abubakar, 1998; Ayodele and Abubakar, 2001; Ayodele and Bayero, 2008, 2009).

\section{Statistical Analysis}

All statistical computations were on the PC 486 $66 \mathrm{MHZ}$ microcomputer using the integrated statistical package for windows from Umstat Ltd. (London) or dedicated micro instructions for Excel spread sheets from Microsoft. The approach enabled the advantages of the various computational and graphical facilities of both types of software's to be used with the ability to read different file formats. The analysis of variance (ANOVA) was carried out according to described procedures (O'Mahony, 1986).

\section{RESULTS AND DISCUSSION}

The frequency distribution pattern for the age of donors is as shown in Figure1.The distribution is multimodal with a mean age of $25.01 \pm 11.46$ years. The frequency distribution pattern for cobalt in toenail is as shown in Figure 2.The distribution is multimodal and is skewed towards low frequency of high concentration with a mean and standard deviation of $76.53 \pm 26.77 \mu \mathrm{g} / \mathrm{g}$ while the frequency distribution pattern for zinc 


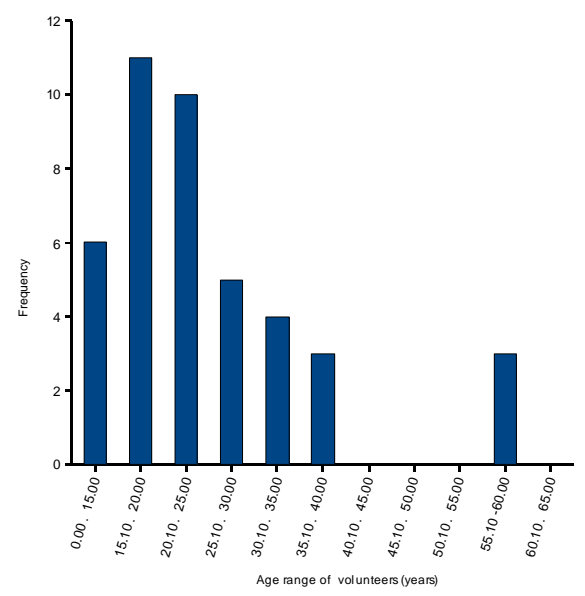

in toenails (Figure 3 ) is multimodal and is skewed towards Figure 1: Frequency Distribution Pattern for the age of Donors (Years)

(a)

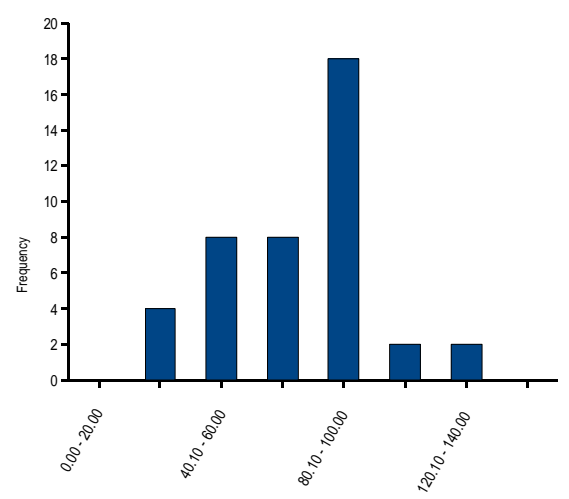

(b)

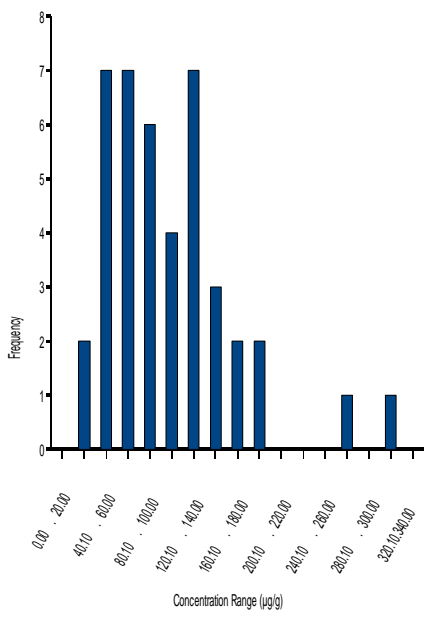

Figure 2: Frequency Distribution pattern for Cobalt (a) and Zinc (b) in toenails $(\mu \mathrm{g} / \mathrm{g})$ low frequency of high concentration with a mean and standard deviation of $108.51 \pm 61.40 \mu \mathrm{g} / \mathrm{g}$. Pearson parameric correlation showed a significant correlation between the cobalt and zinc contents in toenail Table 1. The analysis of variance (ANOVA) revealed that the mean cobalt concentration in toenail is significantly different from that of zinc.

Table1: Parametric Pearson correlation coefficients for cobalt and zinc in toenails

\begin{tabular}{lll}
\hline & Cobalt & Zinc \\
\hline Cobalt & 1 & $923^{* *}$ \\
Zinc & $923^{* *}$ & 1 \\
\hline$* *$ Correlation & significant at the & 0.01 level (1-tailed); \\
$\mathrm{N}=42$ &
\end{tabular}

(a)

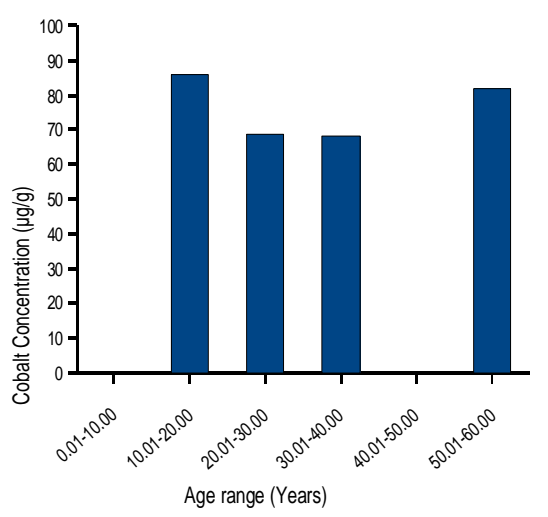

(b)

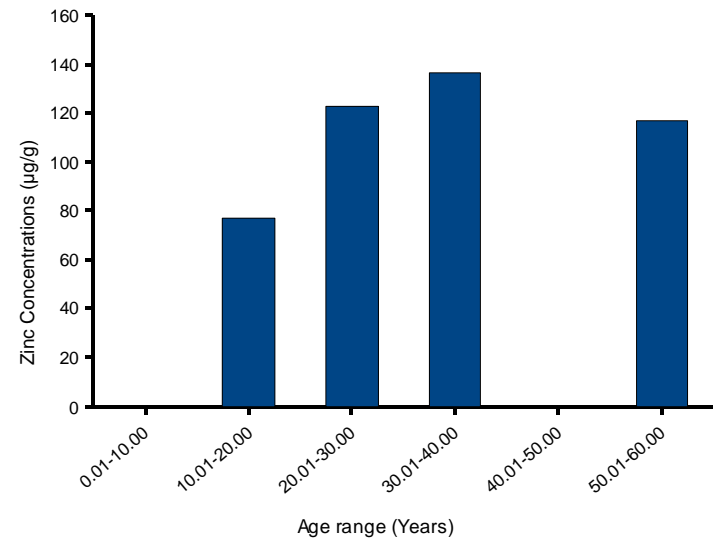

Figure 3: Cobalt (a) and zinc (b) concentrations with respect to age

Cobalt and zinc concentrations in toenails with respect to age are as shown in Figure 3. There 
was no ordered pattern for cobalt in toe nails but a progressive increase in $\mathrm{Zn}$ concentrations in toenails with age indicating that the metal may be playing some physiological functions during the formative years. There was increase relation in zinc concentrations with age with approximate average of $18 \%$ in its concentrations with each decade of age (Guallar et al., 2005). Toenails can record the level and changes of elements in the body over a long period of time (Saiki et al., 1998; Khuder et al., 2008) Changes in the elemental composition of toenails therefore depend on alterations of external and internal media of the human body, and is considered that toenails of healthy individuals contain each element and are potential indicator of both external and internal long-term exposure to pollutants. The idea of toenail analysis is inviting, since it is painlessly removed, normally discarded, easily stored and transported to the laboratory for analysis. The analysis is simple and painless,s trace metal concentrations are not subjected to rapid fluctuations due to diet or other variables and therefore reflect a long term nutritional status. Samples are stable at room temperature, analytical methods are easy because metal concentrations in toenails are relatively high (Borel and Anderson, 1984).

\section{CONCLUSION}

Evaluation of cobalt and zinc in human tissues such as toenails has proved useful in studies pertaining to body exposures. It can be suggested as indexes to evaluate environmental exposures to toxic trace metals (Nord et al., 1973; Flynn, 1977). Trace elements profiles of human toenails may be linked to an individual identity in the same way a hair and fingerprints (Bates and Dyer, 1965) since this tissue after a rapid growth remains somewhat isolated from the metabolic activities of the human body trace elements accumulated in it to reflect largely its exposure. Toenails are useful biomarkers for exposure to contamination. This study has confirmed that a factor such as age is important and should be considered when investigating the potential exposure of human populations to environmental metal concentrations. However, in using these measures, it is necessary to demonstrate that washing in contaminated water causes minimal external contamination. Toenail metals are better surrogate because of the improved correlations with environmental concentrations compared with hair. Diet, metabolism and exposure to environmental contaminants all contribute to trace element concentration in nails. The observed associations between concentrations in toenails are reflective of a combination of factors .This study provides insight into the association between trace element status and disease, establishing a basis for future investigations.

\section{REFERENCES}

ATSDR/EPA(2003).Priority List for2003,Top 20 Hazardous Substances, Agency for Toxic substances and Diseases and Regestry ,U.S. Department of Health and human Services, www.atsdr.cdc.gov/clist.html.

Ayodele, J.T. and Bayero, A.S. (2008). Nickel and Iron concentration in Hair and Nail of some Kano inhabitants Int. J. Pure Appl. Sci Scientia Afr. 7:1-9.

Ayodele, J.T. and Abubakar, M.B. (1998). Trace element contamination of rain water in the semi arid region of Kano .Environ. Manag. Health 9: 179-81.

Ayodele, J.T. and Abubakar, M.B. (2001). Cleopatra bulimoides and Mutella rubens as bioindicators of trace metals in Tiga Dam,Kano Nigeria. Res. J. sci.7: 45-49.

Ayodele, J.T. and Bayero, A.S. (2009). Lead and Zinc concentrations in hair and Nail of some Kano inhabitants Afr. J. Environ. Sci. Technol.3(3): 164-170.

Bates, L.C. and Dyer, F.F. (1965). Trace Elements in human hair. Nucleonics 10: 7481.

Borel, J.S. and Anderson, R.A. (1984). Chromium. In: Frieden E. (ed.), 2000, Biochemistry of the Essential Ultra trace Elements. Plenum Publishers, New York.

Chaudary, K., Ehmann, W.D., Rengan, K. and Markesbery, W.R. (1995). Trace Element correlation of age and sex in human finger nails., J. Radioanal. Nucl. Chem. 195: 55-66

Flynn, A. (1977). Hair elemental analysis as a measure of minerals status. J. Appl. Nutri. 29: 51-54.

Gammelgaard, B., Peters, K. and Menno, T. (1991). Reference values for the nickel concentration in human finger nails. J. Trace Elem. Electrolytes Health Dis. 5: 121-123. 
Gibson, R.S. (1989). Zinc nutrition in developing countries. Nutr. Res. Rev. 7: 151-173.

Guallar, E., Javier, F., Van 't Veer, P., Bode, P., Riemersma, R.A., Gómez-Aracena, J., Kark, J. D., Arab, L., Kok, F. J. and MartínMoreno, J.M. (2005). Low Toenail Chromium Concentration and Increased Risk of Nonfatal Myocardial Infarction. Am. J. Epidemiol. 162(2): 157-164.

Guthrie, H.A. and Picciano, M.F. (1995). Human nutrition Washington DC: US Department of Agriculture Human Nutrition information service. St. Lous: Mosby year book 5:55 ï 60

Hambidge, K.M and Krebs, N.F. (1987). Zinc In: Mertz W. (ed). Trace elements in Human and Animal nutrition. Vol. 2, $5^{\text {th }}$ ed. Academic press New York. Pp. 1 ï 137.

Hayashi, M., Yamamoto, K., Yoshimur, M., Hayashi, H. and Shitara, A. (1993). Cadmium, lead and zinc concentration in human finger nails. Bull. Environ .Contam Toxicol.50: 547- 553.

IAEA International Atomic Energy Agency (1997). The assessment of levels and Health i effects of Airbone particyle Matter in Mining, metal Refining and Metal Working Industries using Nuclear and Related Analytical Techniques, IAEA, Vienna.

Khuder, A., Bakir, M.A., Hasan, R. and Mohammed, A. (2008). Determination of nickel, copper, zinc and lead in human scalp hair in Syrain occupationally exposed workers by total reflection X-ray fluorescence. Environ. Monit. Assess. 143: 67-74.

Krebs, C.J., Boutin, S., Boonstra, R., Sinclair, A. R.E., Smith, J.N.M., Dale, M.R.T., Martin, K. and Turkington, R. (1995). Impact of food and predation on the snowshoe Hare cycle. Science 269: 1112-1115.

Kucera, J., Lener, J., Soukal, L. and Horakova, J. (1996). Air pollution and Biological monitoring of environmental exposure to vanadium using short-time neutron activation analysis. J. Trace and microprobe Techiques.141(2): 191 ï 201.

Mehra, R. and Juneja, M. (2005). Fingernails as biological indices of metal exposure. $J$. Biosci. 30: $101-105$.
Miller, E.R., Stove, H.D., Ulrey, D.E. and Hill, G.M. (1979). Copper and Zinc in swineutrition. National feed ingredients Association literature review on copper and zinc in animal nutrition. National ing. Assic. West Des moines. 1A., 139.

Nielsen, F.H. (2002). Trace Minerals Deficiencies. Handbook of Nutrition and Food. Pp 1463-1487.

Nord, P.J., Kadaba, M.P. and Sorensen, J.R.J. (1973). Mercury in human hair. Arch. Environ. Health 27: 40-44.

OâMahony, M. (1986). Sensory Evaluation of food. Statistical methods and procedures. Marcel Dekker Inc. New York USA.

Oluwole, A.F., Ojo, J.O., Durosimmi, M.A., Asubiojo, O.J., Akunte, O.A., Spyrou, N.M. and Filly, R.H. (1994). Elemental composition of head hair and fingernails of some Nigerian subjects. Biol.Trace Elem. Res. 43: 443 ï 452.

Saiki M, Vasconcellos M.B.A, de Arauz LJ, and Fulfaro R. (1998). Determination of trace Elements in Human Head by Neutron Activation Analysis. $J$ of Radio analytical and Nuclear Chemistry 236(1-2):25-28

Schumacher,M.,Domingo,J.L.,Ljobet,J.M and Corbella, J. (1991). Lead in childrenôs hair as related to exposure in Terragona province, Spain. Sci Total Environ. 104: 107-117.

Soliman, A.S., Wang, X., Stanley, D., ElGhawalby, N., Bondy, M.L., Ezzat, F. Soultan, A., Abdel-Wahab, M. and Fathy, O. (2006). Geographical clustering of pancreatic cancers in the northeast of Egypt. Arch. Env. Cont. Toxicol. 51(1): 142 ï 148.

Vance, D.E, Ehman, W.D. and Markesbery, W.R. (1998). Trace element content in fingernails and hair of non industrised US control population. Biol. Trace Elem. Res. 17: 109 ï 121.

Wolfsperger, M.G., Hauser, W., Gobler, W. and Schlagenhaufen, C. (1994). Heavy metals in human hair samples from Austria and Italy influence of sex and smoking habits. Sci Total Environ. 156: 235-242. 